\title{
Atmospheric moisture transport: the bridge between ocean evaporation and Arctic ice melting
}

\author{
L. Gimeno ${ }^{1}$, M. Vázquez ${ }^{1}$, R. Nieto ${ }^{1}$, and R. M. Trigo ${ }^{2}$ \\ ${ }^{1}$ EPhysLab (Environmental Physics Laboratory), Universidad de Vigo, Facultad de Ciencias, Ourense, Spain \\ ${ }^{2}$ University of Lisbon, CGUL, IDL, Lisbon, Portugal \\ Correspondence to: L. Gimeno (1.gimeno@uvigo.es)
}

\begin{abstract}
Changes in the atmospheric moisture transport have been proposed as a vehicle for interpreting some of the most significant changes in the Arctic region. The increasing moisture over the Arctic during the last decades is not strongly associated with the evaporation that takes place within the Arctic area itself, despite the fact that the sea ice cover is decreasing. Such an increment is consistent and is more dependent on the transport of moisture from the extratropical regions to the Arctic that has increased in recent decades and is expected to increase within a warming climate. This increase could be due either to changes in circulation patterns which have altered the moisture sources, or to changes in the intensity of the moisture sources because of enhanced evaporation, or a combination of these two mechanisms. In this short communication we focus on the more objective assessment of the strong link between ocean evaporation trends and Arctic Sea ice melting. We will critically analyse several recent results suggesting links between moisture transport and the extent of sea ice in the Arctic, this being one of the most distinct indicators of continuous climate change both in the Arctic and on a global scale. To do this we will use a sophisticated Lagrangian approach to develop a more robust framework on some of these previous disconnecting results, using new information and insights. Results reached in this study stress the connection between two climate change indicators, namely an increase in evaporation over source regions (mainly the Mediterranean Sea, the North Atlantic Ocean and the North Pacific Ocean in the paths of the global western boundary currents and their extensions) and Arctic ice melting precursors.
\end{abstract}

\section{The outstanding role of Arctic climate within the global climate system}

The last IPCC Assessment Report has confirmed that the main components of the climate system have been warming (atmosphere, oceans) or shrinking (cryosphere) since the 1970 s, as a result of global warming induced by the significant increment in concentration of greenhouse gases of anthropogenic origin (AR5, IPCC, 2013). The so-called hiatus in the rise of global air temperature since the late 1990s is observed neither in the relentless decadal shift of temperature distributions in both hemispheres (Hansen et al., 2012) nor in the frequency of extreme hot events over the continents (Seneviratne et al., 2014). The much larger capacity of the oceans to store heat, with respect to the atmosphere, has played a fundamental role in storing the excessive heat retained in the climate system in the Pacific (Kosaka and Xie, 2013) and the Atlantic (Chen and Tung, 2014) oceans.
However, global warming is a very uneven phenomenon impossible to be encapsulated by a single indicator relative to one subsystem, such as the global average of near-surface atmospheric temperature. The spatial pattern of observed temperature trends is very asymmetrical and regionalized, with continents warming more than oceans, and with high latitudes also presenting considerably higher warming rates than midlatitude and tropical regions. In particular, several authors have shown that the rise in Arctic near-surface temperature (AST) has been twice as large as the global average throughout most of the year (e.g. Screen and Simmonds, 2010; Tang et al., 2014; Cohen et al., 2014). Additionally, the evolution of the climate in the Arctic region is often associated with two important indicators - the summer and autumn sea ice extent (SIE) and the spring and summer snow cover extent (SCE) - both characterized by a very significant decline since the 1970s and widely recognized as some of the 
most undeniable indicators of continuous climate change affecting the climate system (Tang et al., 2014; IPCC, 2013).

Nevertheless, the opposite evolution of AST and SIE indices in recent decades emphasizes that both phenomena are not independent and, actually, are known to reinforce each other (Tang et al., 2014), as changes in surface albedo (associated with melting snow and ice) tend to enhance warming in the Arctic (Serreze and Francis, 2006) as shown in the recent review paper by Cohen et al. (2014). Nevertheless both indicators (AST and SIE) may also respond to other mechanisms including changes in atmospheric circulation patterns (Graversen et al., 2008), ocean circulation (Comiso et al., 2008), and changes in radiative fluxes associated with cloud cover and water vapour content in the atmosphere (Schweiger et al., 2008; Kapsch et al., 2013), through the absorption of the outgoing long-wave radiation from the surface by the increased atmospheric moisture and then remitted toward the Arctic surface, resulting in the surface warming and sea ice decline (Kapsch et al., 2013). In particular, changes in the atmospheric moisture have been proposed as a vehicle for interpreting the most significant changes in the Arctic region either due to increased transport from middle latitudes (Lucarini and Ragone, 2011; Zanhg et al., 2012) or via enhanced local evaporation (Bintanja and Selten, 2014). However, some recent studies have shown that the evaporation from the Arctic surface appears not to be an important moisture source (e.g. Graversen et al., 2008; Park et al., 2015).

According to some authors, the recent rise on the incidence of summer extreme weather events over Northern Hemisphere continental land masses (Coumou and Rahmstorf, 2012; Seneviratne et al., 2014) is probably driven by the accelerated decline of summer SIE and SCE observed in recent decades (Francis and Vavrus, 2012; Tang et al., 2014). According to this hypothesis, the observed weakening of poleward temperature gradient triggered changes in atmospheric circulation, namely slower progression of Rossby waves (Francis and Vavrus, 2012) and the existence of a planetary-scale wave life cycle (Bagget and Lee, 2015) that is highly amplified (blocking) despite a reduced meridional temperature gradient (consistent with Francis and Vavrus, 2012). These mechanisms have favoured more persistent weather conditions that are often associated with extreme weather events, such as the mega heatwave in Russia in 2010 (Barriopedro et al., 2011) or the long drought in central USA (Coumou and Rahmstorf, 2012). However, there is currently much debate on the nature of mechanism(s) responsible for this increment of persistent weather patterns associated with such extreme climatic events (Cohen et al., 2014), with some authors suggesting other drivers (albeit equally exacerbated by global warming), such as the role of drying soils associated with earlier SCE melting (Tang et al., 2014) or simply related to tropical extratropical interactions (Palmer, 2014). According to Cohen et al. (2014) there are three major dynamical frameworks to propagate the anomalous cli- mate signals originating in the Arctic (namely changes in SIE and SCE) toward midlatitudes: (1) changes in storm tracks, (2) changes in the characteristics of the jet stream, and (3) anomalous planetary wave configurations triggered by regional changes in the tropospheric circulation. Tang et al. (2014) compared the role played by both SIE and SCE in what concerns their capacity to change atmospheric circulation and inducing extreme summer extremes in northern midlatitudes. These authors have found that despite the stronger decrease in SCE compared to SIE, the latter provides a stronger response in terms of atmospheric circulation anomalies. Often related with climatic extremes, Tang et al. (2014) provide evidence that the combined reductions of SIE and SCE are associated with "widespread upper-level height increases, weaker upper-level zonal winds at high latitudes, a more amplified upper-level pattern, and a general northward shift in the jet stream".

Considering all the above reasons the Arctic sector emerges as the most sensitive region of the climate system to the effects of global warming, but it also represents an area where current and future changes are bound to affect the climate at a much larger scale (Screen and Simmonds, 2010; Tang et al., 2014; Cohen et al., 2014).

\section{Main mechanisms relating sea ice decline and increased moisture transport}

The atmospheric branch of the hydrological cycle plays a fundamental role in establishing the link between the Arctic system and the global climate. However, to the best of our knowledge, this role has not been fully accounted for objectively, although the transport of moisture from the extratropical regions to the Arctic has increased in recent decades (Zhang et al., 2012), and it is expected to further increase under global warming, independently of the climate change scenario considered (Kattsov et al., 2007). Some works try to explain extreme events of atmospheric moisture transport to the Arctic through the occurrence of atmospheric rivers (Woods et al., 2013) and Rossby wave breaking events (Liu and Barnes, 2015). The general increase of moisture could be due to changes in circulation patterns, which have altered the location of the most important moisture sources, or it could be the result of changes in the magnitude of the existing moisture sources as a consequence of enhanced evaporation, or a combination of these two mechanisms (Gimeno et al., 2012, 2013).

Most studies of changes on moisture transport towards the Arctic climate make use of one of three possible techniques, namely (1) Eulerian approaches (e.g. Jakobson and Vihma, 2010), which can be used to estimate the ratio of advectedto-recycled moisture and to calculate the moisture transport between predetermined source and sink regions; (2) isotope analysis (e.g. Kurita, 2011), but neither this nor the Eulerian techniques are capable of a proper geographical identifica- 
tion of the sources; or (3) more complex Lagrangian computational techniques that are able to infer the sources of the precipitation that falls in a target region and thus overcome the limitations of (1) and (2). An analysis of the performance of these Lagrangian techniques and their advantages over Eulerian and isotope analysis was recently given by Gimeno et al. (2012). Here we will critically analyse some of the previous assessments that have established the link between moisture transport from midlatitudes towards the Arctic region and changes in Arctic SIE. In addition, we will use a sophisticated Lagrangian approach to contrast these existing results using new information and insights.

In recent years a number of mechanisms have been put forward relating the strength of moisture transport and Arctic SIE. These mechanisms vary significantly in the nature of their main driver, including the following: (i) hydrological drivers, such as increments in Arctic river discharges (Zhang et al., 2012) or increments in precipitation due to enhanced local evaporation due to less SIE (Bintanja and Selten, 2014); (ii) radiative drivers, particularly through rises in cloud cover and water vapour (Kapsch et al., 2013); and (iii) dynamical drivers, namely more summer storms with unusual characteristics crossing the Arctic (Simmonds and Rudeva, 2012). Most likely these different mechanisms coexist to a certain extent and are not necessarily mutually exclusive. For instance the autumn and early positive trend is SCE (Estilow et al., 2015), which can be closely related to positive trends in Eurasian rivers (Yang et al., 2007). In particular, two of these works (Zhang et al., 2012; Kapsch et al., 2013) provide novel insight on the role played by the transport of moisture and the melting of sea ice or snow cover. Their main findings are summarized below:

1. According to Zhang et al. (2012) in their work entitled "Enhanced poleward moisture transport and amplified northern high-latitude wetting trend", the authors provide strong evidence to support (i) that there is a trend in the net poleward atmospheric moisture transport (AMT) towards the Eurasian Arctic river basins, (ii) that this net AMT is captured in $98 \%$ of the gauged climatological river discharges, and (iii) that the upward trend of $2.6 \%$ net AMT per decade is in good agreement with the $1.8 \%$ increase per decade in the gauged discharges.

The increase in Arctic river discharge is a possible cause of sea ice melting in agreement with several studies realized over the Canadian Arctic region that support these results (e.g. Dean et al., 1994; Nghiem et al., 2014). Thus, AMT can be seen to have an important role to play in this process. Nevertheless, Zhang et al. (2012) used a very simple analysis of integrated moisture fluxes, in which they calculated moisture transport from predetermined source and sink regions, and they were unable to identify the moisture source regions directly.
2. Using a very different methodology Kapsch et al. (2013), in the paper entitled "Springtime atmospheric energy transport and the control of Arctic summer sea-ice extent", demonstrated that in areas of summer ice retreat, a significantly enhanced transport of humid air is evident during spring, producing increased cloudiness and humidity resulting in an enhanced greenhouse effect.

As for Kapsch et al. (2013), global balances of atmospheric moisture flux were used, which allowed neither the identification of the moisture sources nor any assessment of their role in the variability of the moisture transport.

\section{Identifying objectively the main sources of moisture for large Eurasian river basins}

The analysis adopted here to discuss existing results is mostly based on the Lagrangian particle dispersion model FLEXPART (Bintanja and Selten, 2014; Stohl and James, 2004), using data from 1979 to 2013 obtained from the ERAInterim reanalysis of the ECMWF (Dee et al., 2011), which can be considered the state-of-the-art reanalysis in terms of the hydrological cycle (Trenberth et al., 2011; Lorenz and Kunstmann, 2012). The analysis will be restricted to years after 1979 in order to avoid working with results obtained prior to the incorporation of satellite data in the reanalysis. Using a horizontal resolution of $1^{\circ}$ in latitude and longitude and a resolution of 61 vertical levels, the algorithm tracks atmospheric moisture along trajectories. A 3-D wind field moves a large number of so-called particles (air parcels) resulting from the homogeneous division of the atmosphere. The specific humidity $(q)$ and the position (latitude, longitude and altitude) of all the particles are recorded at $6 \mathrm{~h}$ intervals. The model then calculates increases $(e)$ and decreases $(p)$ in moisture along each trajectory at each time step by means of variations in $q$ with respect to time (i.e. $e-p=m \mathrm{~d} q / \mathrm{d} t$ ). The quantity $(E-P)$ is calculated for a given area of interest by summing $e-p$ for all particles crossing a $1^{\circ}$ grid column of the atmosphere, where $E$ and $P$ are the rates of evaporation and precipitation, respectively. The particles are tracked and a database is created with values of $E-P$ averaged and integrated over 10 days of transport, this being the average residence time of water vapour in the atmosphere (Numaguti, 1999). The main sources of moisture for the target area (in terms of when and where the air masses that reach the target area acquire or lose moisture) are shown through the analysis of the 10-day integrated $E-P$ field. For a comprehensive review see Gimeno et al. (2012), which provides details of the limitations of this Lagrangian approach, its uncertainty and significance, and its advantages and disadvantages with respect to other methods of estimating moisture sources. For further information on FLEXPART model see Stohl et al. (2004). 


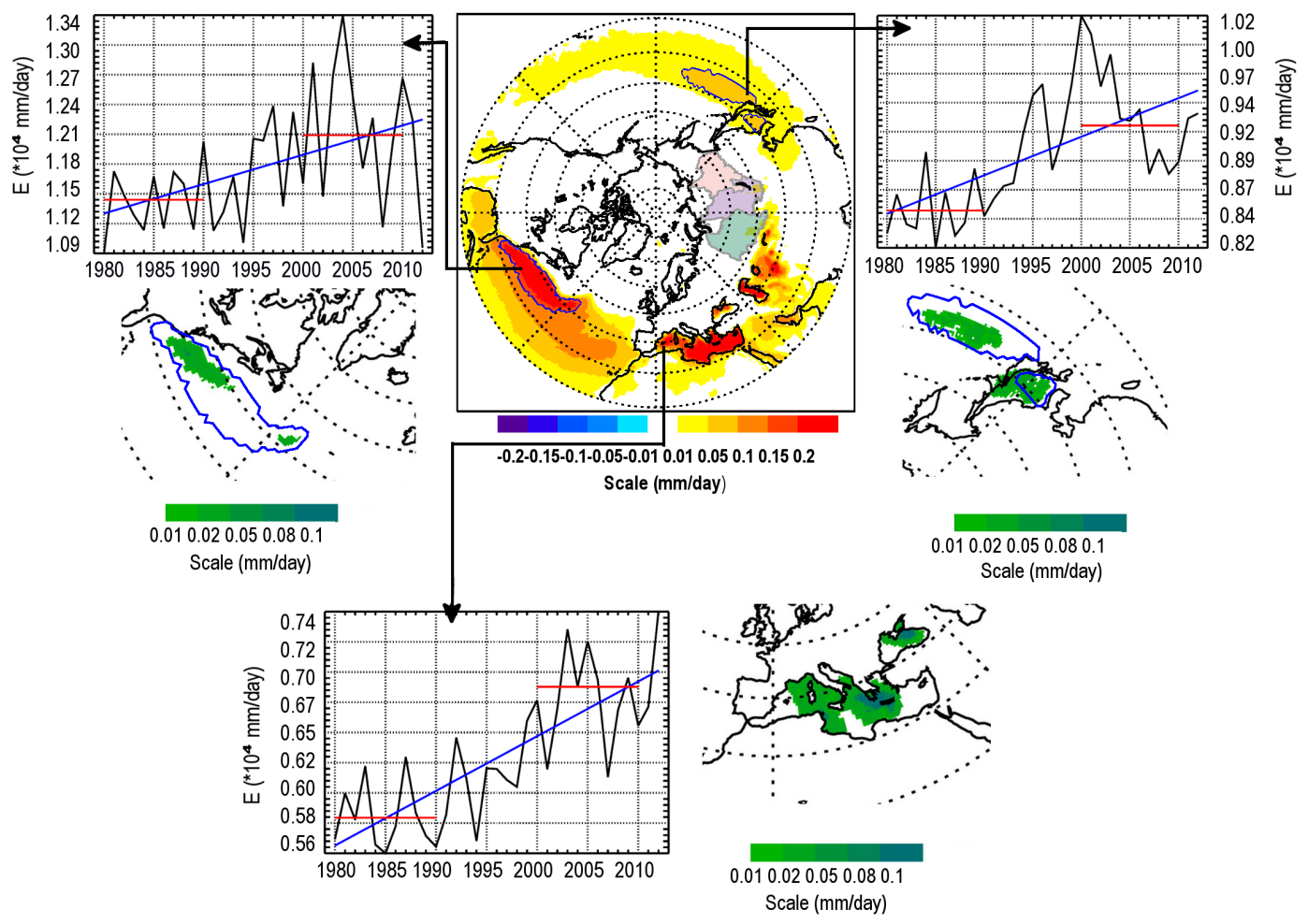

Figure 1. Centre panel: climatological October-March 10-day integrated $(E-P)$ values observed for the period 1979-2012, for all the particles bound for the $\mathrm{Ob}$, Yenisei and Lena river basins (green, purple and pink areas respectively indicate the basin area), determined from backward tracking. Warm colours represent regions acting as moisture sources for the tracked particles. Plots in green show the significant positive differences at the $95 \%$ level after bootstrap test (1000 interactions) in the composites of the moisture sources of the Arctic river basins between the decades 2001-2010 and 1981-1990. Temporal series show the evolution of the average evaporation derived from OAFlux data set for the main moisture sources for the Arctic river basins (the Atlantic and Pacific sources, those circled with a blue line in the central figure, and for the whole Mediterranean Sea basin). The blue lines are the linear trend and the red ones denote the 10-year periods used on composites.

According to Zhang et al. (2012), temporal lags must be considered when linking AMT from lower latitudes with snowpack accumulation and also between this and Arctic river discharges. Thus, summer Arctic river discharge can be related to the result of the melting of the snowpack that accumulated during the preceding months, while the AMT most related to the summer river discharge corresponds to that resulting from snowpack accumulation during the period October-March. We therefore choose this period to estimate the moisture sources for the target region formed by the $\mathrm{Ob}$, Yenisei and Lena river basins, as in the work of Zhang et al. (2012). The central panel of Fig. 1 shows that the main moisture sources are located over the Mediterranean Sea, and the smaller Caspian and Black seas, as well as the North Atlantic Ocean and to a somewhat lesser degree the North Pacific Ocean in the paths of the global western boundary currents and their extensions. This result is striking because these source regions seem to match those areas with the highest trends in terms of evaporation in the past few decades.

\section{Trends in evaporation from main sources: possible consequences}

Using some of the best estimates of evaporation, namely those derived from the OAFlux data (Yu and Weller, 2007), strong increasing trends can be seen in evaporation from the oceans since 1978, with the upward trend being most pronounced during the 1990s. The spatial distribution of these trends (Yu, 2007) shows that while the increase in evaporation has occurred globally, it has primarily been observed during the hemispheric winter and is strongest along the paths of the global western boundary currents and any inner seas with wind forcing playing a dominant role. According to $\mathrm{Yu}$ (2007) and after performing an empirical orthogonal function (EOF) analysis of evaporation and its related variables (wind speed and air-sea humidity differences), the wind forcing is mainly responsible for the decadal change through two mechanisms: one direct - "greater wind speed induces more evaporation by carrying water vapour away from the evaporating surface to allow the air-sea humidity gradients to be reestablished at a faster pace" - and a 


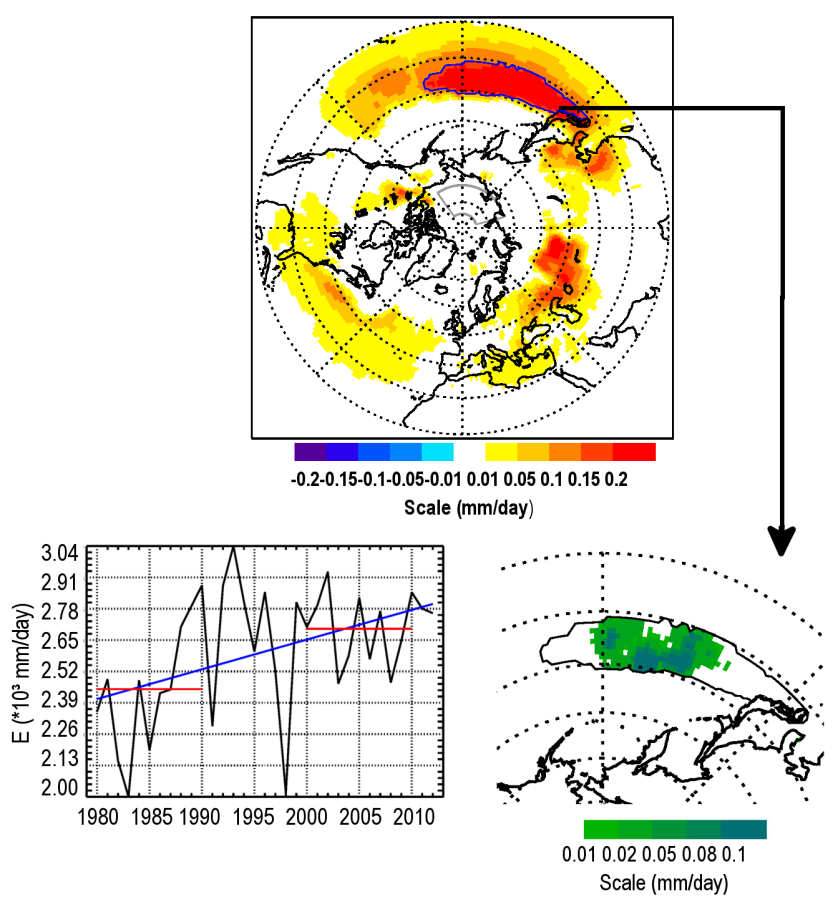

Figure 2. As Fig. 1 but for the Kapsch area $\left(75-85^{\circ} \mathrm{N}, 115-\right.$ $215^{\circ} \mathrm{E}$ ), denoted with the grey contour in the bottom panel.

second one indirect - "the enhanced surface wind strengthens the wind-driven subtropical gyre, which in turn drives a greater heat transport by the western boundary currents, warms up SST along the paths of the currents and extensions, and causes more evaporation by enlarging the airsea humidity gradients". The EOF analysis also showed that the interannual variability of evaporation occurred on similar timescales to those of the El Niño-Southern Oscillation. Figure 1a-c also show the evolution of the average evaporation derived from OAFlux for the main moisture sources for the Arctic river basins (those circled with a blue line and the entire Mediterranean Sea basin). Although important, interannual variability superimposed to a pronounced decadalscale variability previously commented, trends are significant in most of the grid points encircled and are especially clear for the Atlantic, Pacific and Mediterranean sources. Similar results were reached when evaporation taken from ERA-Interim was used (not shown). The differences in the composites of the moisture sources of the Arctic river basins between the decade 2001-2010 and the decade 1981-1990 are also shown in Fig. 1, with greenish colours indicating regions where their contribution as a source intensified over these years. From these results it seems clear that there is an enhanced moisture contribution from those moisture regions where the evaporation increased.

We have repeated the procedure considering the region analysed by Kapsch et al. (2013). That is, in this case, the late spring (April and May) moisture sources detected are re- lated to the area where the September sea ice anomaly is encountered. Overall results (Fig. 2) are quite similar to those presented for the Arctic river basins, and the main moisture sources are also placed in the paths of the global western boundary currents in both the North Atlantic and the North Pacific oceans (the main one in this case) and in the Mediterranean basins (more moderate in this case).

In this regard the intensification of evaporation in these source regions could have a dual effect on the reduction of September Arctic ice, through (1) intensification of summer river discharge and (2) enhancement of the greenhouse effect due to an increase in cloudiness and humidity over the icemelting regions.

\section{Summary and conclusions}

We have made a critical assessment of the results obtained in two important recent works that offer new understanding of the role played by the transport of moisture and the melting of sea ice or snow cover (Zhang et al., 2012; Kapsch et al., 2013). The Lagrangian analysis adopted in our approach stresses the connection between two climate change indicators, namely an increase in evaporation over source regions and Arctic ice melting. We are confident that our results provide the necessary link between these two realms and suggest an intricate chain of events related to (1) positive trends in evaporation in specific ocean areas that correspond to the main moisture source regions of Eurasian rivers, (2) upward trends in atmospheric transport from these regions to the Arctic river basins/regions where ice-melting occurs, and (3) trends in river discharges/moisture and cloud cover. These developments merit further and more comprehensive study in terms of their effects on present and future climates.

Acknowledgements. The authors acknowledge funding by the European ERA.Net RUS programme, within the project ACPCA and by the Spanish MINECO and FEDER within the project TRAMO.

Edited by: C. Franzke

\section{References}

Baggett, C. and Lee, S.: Arctic warming induced by tropically forced tapping of available potential energy by planetary scale waves, J. Atmos. Sci., 72, 1562-1568, 2015.

Barriopedro D., Fischer E. M., Luterbacher L., Trigo R. M., and García-Herrera R.: The hot summer of 2010: redrawing the temperature record map of Europe, Science, 332, 220-224, doi:10.1126/science.1201224, 2011.

Bintanja, R. and Selten, F. M.: Future increases in Arctic precipitation linked to local evaporation and sea-ice retreat, Nature, 509, 480-482, 2014. 
Chen, X. and Tung, K. K.: Varying planetary heat sink led to globalwarming slowdown and acceleration, Science, 345, 897-903, doi:10.1126/science.1254937, 2014.

Cohen, J., Screen, J. A., Furtado, J. C., Barlow, M., Whittleston, D., Coumou, D., Francis, J., Dethloff, K., Entekhabi, D., Overland, J., and Jones, J.: Recent Arctic amplification and extreme mid-latitude weather, Nat. Geosci., 7, 627-637, doi:10.1038/ngeo2234, 2014.

Comiso, J. C., Parkinson, C. L., Gersten, R., and Stock, L.: Accelerated decline in the Arctic sea ice cover, Geophys. Res. Lett., 35, L01703, doi:10.1029/2007GL031972, 2008.

Coumou, D. and Rahmstorf, S.: A decade of weather extremes, Nat. Clim. Chang., 2, 491-496, 2012.

Dean, K. G., Stringer, W. J., Ahlnas, K., Searcy, C., and Weingartner, T.: The influence of river discharge on the thawing of sea ice, Mackenzie River Delta: albedo and temperature analyses, Polar Res., 13, 83-94, doi:10.1111/j.1751-8369.1994.tb00439.x, 1994.

Dee, D, Uppala, S. M., Simmons, A. J., Berrisford, P., Poli, P., Kobayashi, S., Andrae, U., Balmaseda, M. A., Balsamo, G., Bauer, P., Bechtold, P., Beljaars, A. C. M., van de Berg, L., Bidlot, J., Bormann, N., Delsol, C., Dragani, R., Fuentes, M., Geer, A. J., Haimberger, L., Healy, S. B., Hersbach, H., Hólm, E. V., Isaksen, L., Kållberg, P., Köhler, M., Matricardi, M., McNally, A. P., Monge-Sanz, B. M., Morcrette, J. J., Park, B. K., Peubey, C., de Rosnay, P., Tavolato, C., Thépaut, N., and Vitart, F.: The ERA Interim reanalysis: Configuration and performance of the data assimilation system, Q. J. Roy. Meteorol. Soc., 137, 553597, doi:10.1002/qj.828, 2011.

Estilow, T. W., Young, A. H., and Robinson, D. A.: A long-term Northern Hemisphere snow cover extent data record for climate studies and monitoring, Earth Syst. Sci. Data, 7, 137-142, doi:10.5194/essd-7-137-2015, 2015.

Francis, J. A. and Vavrus, S. J.: Evidence linking Arctic amplification to extreme weather in mid-latitudes, Geophys. Res. Lett., 39, L06801, doi:10.1029/2012GL051000, 2012.

Gimeno, L., Stohl, A., Trigo, R. M., Dominguez, F., Yoshimura, K., Yu, L., Drumond, A., Duran-Quesada, A. M., and Nieto, R.: Oceanic and Terrestrial Sources of Continental Precipitation, Rev. Geophys., 50, RG4003, doi:10.1029/2012RG000389, 2012.

Gimeno, L., Nieto, R., Drumond, A., Castillo, R., and Trigo, R. M.: Influence of the intensification of the major oceanic moisture sources on continental precipitation, Geophys. Res. Lett., 40, 1443-1450, doi:10.1002/grl.50338, 2013.

Graversen, R. G., Mauritsen, T., Tjernstrom, M., Källen, E., and Svensson, G.: Vertical structure of recent Arctic warming, Nature, 451, 53-56, doi:10.1038/nature06502, 2008.

Hansen, J., Sato, M., and Ruedy, R.: Perception of climate change, P. Natl. Acad. Sci., 109, 14726-14727, doi:10.1073/pnas.1205276109, 2012.

IPCC: Climate Change 2013: The physical science basis, in: Contribution of working group 1 to the fifth assessment report of the intergovernmental panel on climate change, edited by: Stocker, T. F., Qin, D., Planttner, G. K., Tignor, M., Allen, S. K., Boschung, J., Nauels, A., Xia, Y., Bex, V., and Midgley, P. M., Cambridge University Press, Cambridge, UK and New York, NY, USA, 2013.

Jakobson, E. and Vihma, T.: Atmospheric moisture budget in the Arctic based on the ERA-40 reanalysis, Int. J. Climatol., 30, 2175-2194, doi:10.1002/joc.2039, 2010.
Kapsch, M. L., Graversen, R. G., and Tjernström, M.: Springtime atmospheric energy transport and the control of Arctic summer sea-ice extent, Nat. Clim. Change, 3, 744-748, doi:10.1038/nclimate1884, 2013.

Kattsov, V. M., Walsh, J. E., Chapman, W. L., Govorkova, V. A., Pavlova, T. V., and Zhang, X.: Simulation and projection of Arctic freshwater bedget components by the IPCC AR4 global climate models, J. Hydrometeorol., 8, 571-589, 2007.

Kosaka, Y. and Xie, S. P.: Recent global-warming hiatus tied to equatorial Pacific surface cooling, Nature, 501, 403-407, doi:10.1038/nature12534, 2013.

Kurita, N.: Origin of Arctic water vapor during the ice-growth season, Geophys. Res. Lett., 38, L02709, doi:10.1029/2010GL046064, 2011.

Liu, C. and Barnes, E. A.: Extreme moisture transport into the Arctic linked to Rossby wave breaking, J. Geophys. Res.-Atmos., 120, 3774-3788, doi:10.1002/2014JD022796, 2015.

Lorenz, C. and Kunstmann, H.: The hydrological cycle in three state-of-the-art reanalyses: Intercomparison and performance analysis, J. Hydrometeorol., 13, 1397-1420, 2012.

Lucarini, V. and Ragone, F.: Energetics of climate models: Net energy balance and meridional enthalpy transport, Rev. Geophys., 49, RG1001, doi:10.1029/2009RG000323, 2011.

Nghiem, S. V., Hall, D. K., Rigor, I. G., Li, P., and Neumann, G.: Effects of Mackenzie River discharge and bathymetry on sea ice in the Beaufort Sea, Geophys. Res. Lett., 41, 873-879, doi:10.1002/2013GL058956, 2014.

Numaguti, A.: Origin and recycling processes of precipitating water over the Eurasian continent: Experiments using an atmospheric general circulation model, J. Geophys. Res., 104, 1957-1972, 1999.

Palmer T.: Record-breaking winters and global climate change, Science, 344, 803-804, doi:10.1126/science.1255147, 2014.

Park, D. S. R., Lee, S., and Feldstein, S. B.: Attribution of the Recent Winter Sea Ice Decline over the Atlantic Sector of the Arctic Ocean, J. Climate, 28, 4027-4033, 2015.

Schweiger, A. J., Lindsay, R. W., Vavrus, S., and Francis, J. A.: Relationships between Arctic sea ice and clouds during autumn, J. Climate, 21, 4799-4810, 2008.

Screen, J. A. and Simmonds, I.: The central role of diminishing sea ice in recent Arctic temperature amplification, Nature, 464, 1334-1337, doi:10.1038/nature09051, 2010.

Seneviratne, S., Donat, M. G., Mueller, B., and Alexander, L. V.: No pause in the increase of hot temperature extremes, Nat. Clim. Change, 4, 161-163, 2014.

Serreze, M. C. and Francis, J. A.: The Arctic amplification debate, Climatic Change, 76, 241-264, 2006.

Simmonds, I. and Rudeva, I.: The great Arctic cyclone of August 2012, Geophys. Res. Lett., 39, L23709, doi:10.1029/2012GL054259, 2012.

Stohl, A. and James, P. A.: Lagrangian analysis of the atmospheric branch of the global water cycle: Part I. Method description, validation, and demonstration for the August 2002 flooding in central Europe, J. Hydrometeorol., 5, 656-678, 2004.

Tang, Q., Zhang, X., and Francis, J. A.: Extreme summer weather in northern mid-latitudes linked to a vanishing cryosphere, Nat. Clim. Change, 4, 45-50, doi:10.1038/nclimate2065, 2014. 
Trenberth, K. E., Fasullo, J. T., and Mackaro, J.: Atmospheric moisture transports from ocean to land and global energy flows in reanalyses, J. Climate, 24, 4907-4924, 2011.

Woods, C., Caballero, R., and Svensson, G.: Large-scale circulation associated with moisture intrusions into the Arctic during winter, Geophys. Res. Lett., 40, 4717-4721, doi:10.1002/grl.50912, 2013.

Yang, D., Zhao, Y., Armstrong, R., Robinson, D., and Brodzik, M.J.: Streamflow response to seasonal snow cover mass changes over large Siberian watersheds, J. Geophys. Res., 112, F02S22, doi:10.1029/2006JF000518, 2007.
Yu, L.: Global variations in oceanic evaporation (1958-2005): The role of the changing wind speed, J. Climate, 20, 5376-5390, 2007.

Yu, L. and Weller, R. A.: Objectively analyzed air-sea heat fluxes for the global ice-free oceans (1981-2005), B. Am. Meteorol. Soc., 88, 527-539, 2007.

Zhang, X., He, J., Zhang, J., Polyakov, I., Gerdes, R., Inoue, J., and $\mathrm{Wu}, \mathrm{P}$. : Enhanced poleward moisture transport and amplified northern high-latitude wetting trend, Nat. Clim. Change, 3, 47-51, doi:10.1038/nclimate1631, 2012. 